Supporting Information

\title{
Characterization and Chromatographic Isolation of Platelet Extracellular Vesicles from Human Platelet Lysates for Applications in Neuroregenerative Medicine
}

Ariunjargal Nyam-Erdene ${ }^{a}$, Ouada Nebie ${ }^{b}$, Liling Delila $^{b}$, Luc Buée $^{c, d, e}$, David Devos ${ }^{c, e}$, SzuYi Chouf,g, David Blum ${ }^{c, d, e}$, Thierry Burnouf ${ }^{a, b, g, h, i *}$

a International PhD Program in Biomedical Engineering, College of Biomedical Engineering, Taipei Medical University, Taipei, Taiwan;

b Graduate Institute of Biomedical Materials and Tissue Engineering, College of Biomedical Engineering, Taipei Medical University, Taipei, Taiwan;

c Université de Lille, Inserm U1172, CHU-Lille, Lille Neuroscience \& Cognition, Lille, France;

${ }^{\mathrm{d}}$ Alzheimer \& Tauopathies, Labex DISTALZ, Lille, France;

e NeuroTMULille International Laboratory, Université de Lille, Lille, France ;

f Ph.D.Program for Neural Regenerative Medicine, College of Medical Science and Technology, Taipei Medical University,

g NeuroTMULille International Laboratory, Taipei Medical University, Taipei, Taiwan;

h International PhD Program in Cell Therapy and Regeneration Medicine, College of Medicine, Taipei Medical University, Taipei, Taiwan;

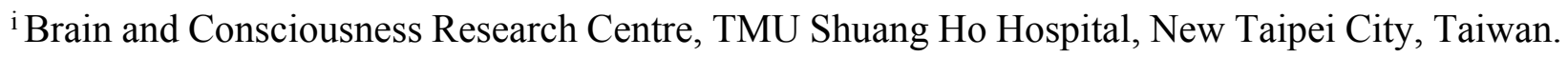

Correspondence: Thierry Burnouf, Graduate Institute of Biomedical Materials and Tissue Engineering, College of Biomedical Engineering, Taipei Medical University, Taipei, Taiwan. Email: thburnouf@gmail.com 
Content: Number of pages:9, Number of figures:5.

\section{Materials and Methods}

\section{Platelet concentrates (PCS)}

Institutional Review Board approval for the study was obtained from Taipei Medical University (TMU-JIRB N201802052) and the Taiwan Blood Services Foundation (Taipei, Taiwan). Clinicalgrade PCs suspended in $100 \%$ plasma were collected by plateletpheresis (MCS+, Haemonetics, Braintree, MA, USA) of healthy volunteer donors at the Taipei Blood Center (Guandu, Taiwan) using Taiwanese Food and Drug Administration-approved procedures. The PCs, no longer suitable for transfusion (5 days after collection) but valuable for possible applications in regenerative medicine or cell therapy ${ }^{1}$, were provided to the laboratory within 6 days after collection and processed within $24 \mathrm{~h}$. Data on blood cell counts (red blood cells, white blood cells, and platelets) were recorded. Three PCs were pooled and split into four groups to prepare the four different types of HPLs as described below.

\section{Preparation of HPLs}

All HPLs were prepared under aseptic conditions as previously described ${ }^{2}$. Briefly, the platelet pellet lysate (PPL) was acquired by centrifugation of the PCs (ca. $200 \mathrm{~mL}$ ) at $3000 \times g$ for $30 \mathrm{~min}$ at $22 \pm 2{ }^{\circ} \mathrm{C}$ to pelletize the platelets. The supernatant was removed, and the platelet pellet was carefully washed with ca. $2 \mathrm{~mL}$ of phosphate-buffered saline (PBS). The platelet pellet was resuspended in PBS (1/10 of the initial volume of the PC) and lysed by three freeze-thaw cycles (- 
$80 / 30{ }^{\circ} \mathrm{C}$ ), followed by centrifugation at $4500 \times g$ for $30 \mathrm{~min}$ at $22 \pm 2{ }^{\circ} \mathrm{C}$. The PPL supernatant was recovered. One aliquot was heated to $56{ }^{\circ} \mathrm{C}$ for $30 \mathrm{~min}$, directly cooled down in an ice bath for $5 \mathrm{~min}$, and then centrifuged $\left(10^{4} \times g\right.$ for $15 \mathrm{~min}$ at $\left.4 \pm 2{ }^{\circ} \mathrm{C}\right)$ to remove any insolubles and obtain the supernatant (HPPL). Serum-converted platelet lysate (SCPL) was acquired by activation of PCs by adding calcium chloride $\left[\mathrm{CaCl}_{2} 10 \%(\mathrm{v} / \mathrm{v}), 30 \mu \mathrm{l} / \mathrm{mL}\right]$ to a final concentration of $23 \mathrm{mM}$, in the presence of sterilized glass beads $(0.5 \mathrm{~g} / \mathrm{mL})$ at room temperature. The fibrin clot created within 60 min was then removed by centrifugation at $6000 \times g$ for $30 \mathrm{~min}$ at $22 \pm 2{ }^{\circ} \mathrm{C}$, and the supernatant (SCPL) was recovered. One aliquot was heated to $56^{\circ} \mathrm{C}$ for $30 \mathrm{~min}$, centrifuged, and the supernatant (HSCPL) was recovered. All HPL fractions were aliquoted and stored at $-80{ }^{\circ} \mathrm{C}$ until analysis. Before all experiments, aliquots were thawed at $37^{\circ} \mathrm{C}$ and spun at $10^{4} \times g$ for $15 \mathrm{~min}$ at $4{ }^{\circ} \mathrm{C}$ to remove any insolubles. 
Figure S1: Chromatogram ( $280 \mathrm{~nm}$ absorbance) of three consecutive runs ( $\mathrm{n}=3)$ of each human platelet lysates (HPLs) onto a SEC-Sepharose CL-2B column. EVs derived from platelet pellet lysate (EV-PPLs), heat-treated platelet pellet lysate (EV-HPPLs), serum converted platelet lysate (EV-SCPLs), and heat-treat serum converted platelet lysate (EV-HSCPLs).

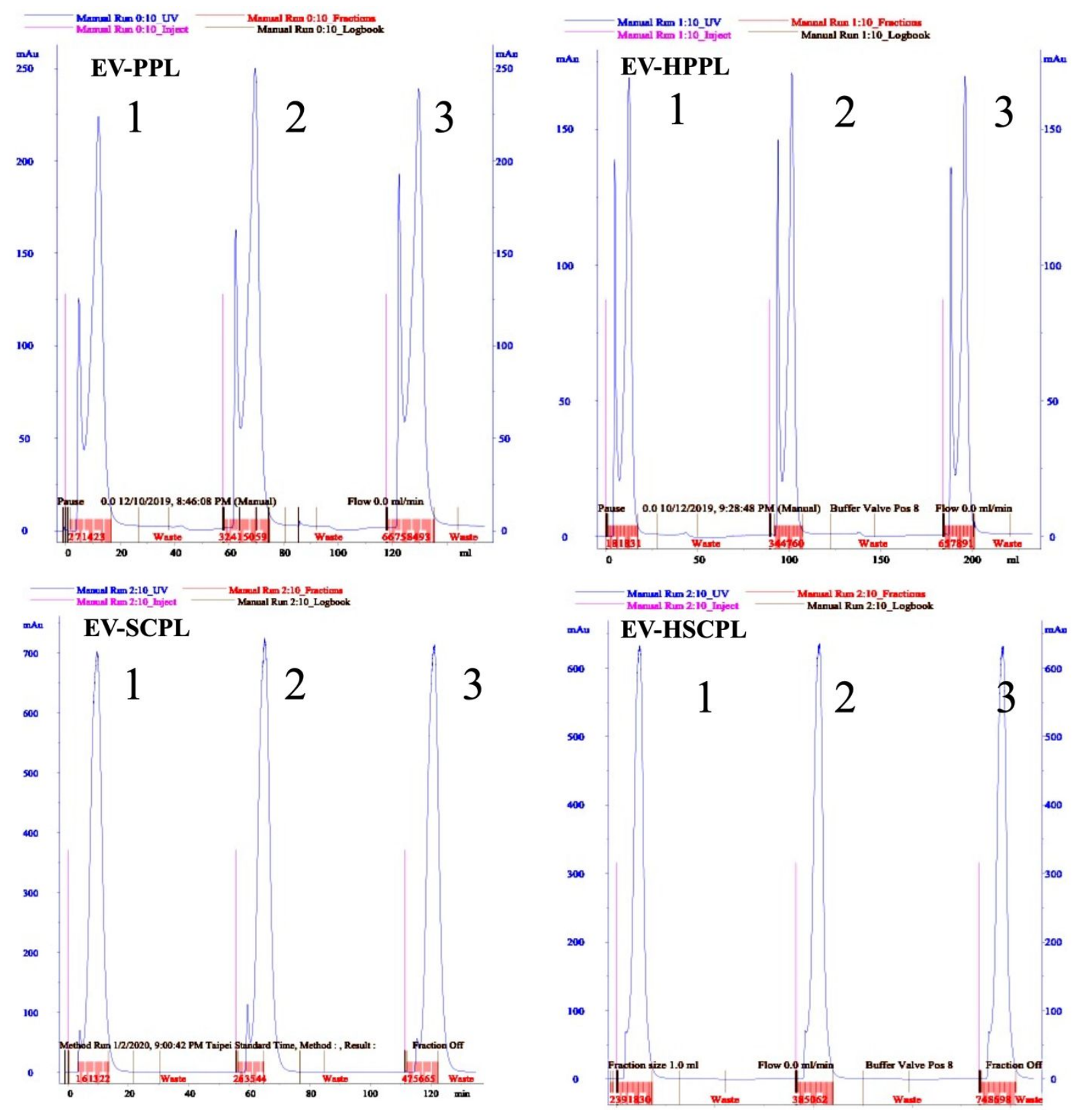


Figure S2: Typical images of the wound healing assay analysis showing conversion into uneven background and highlighting the layer of cells from the wound area to quantify the wound closure by Image $\mathrm{J}$.

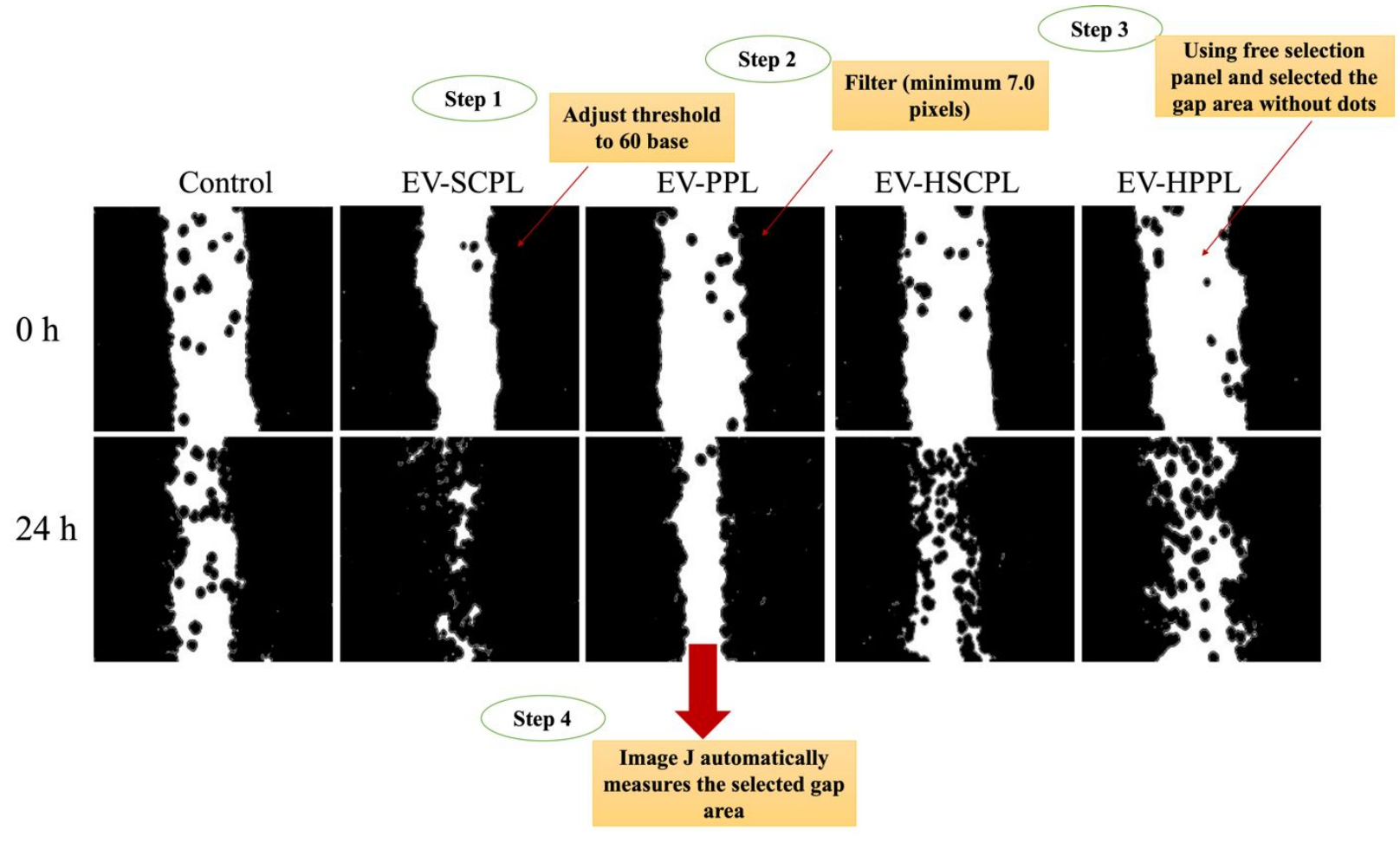


Figure S3: (Full-length gels/blots images)

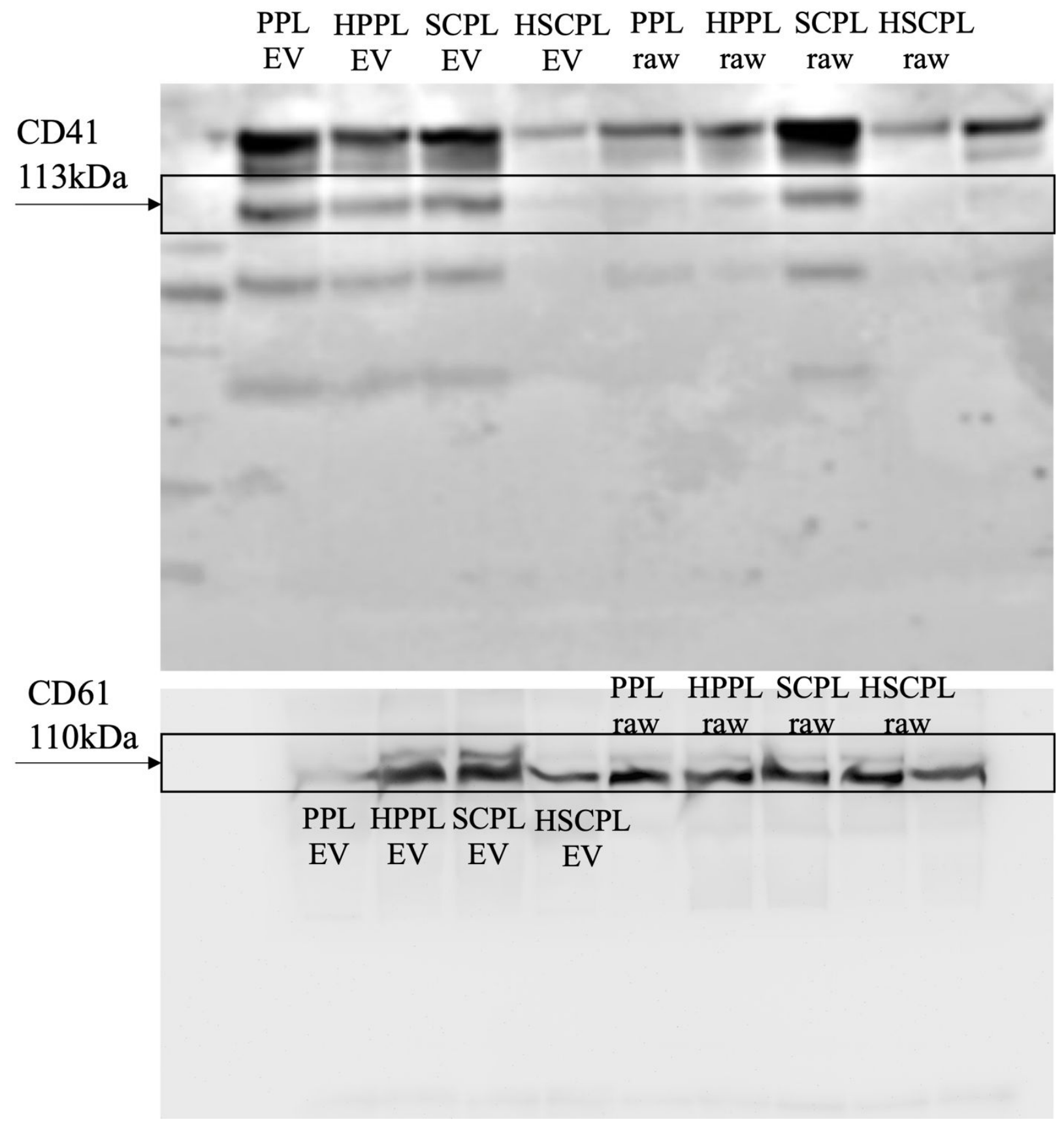


Figure S4: Scratch assessment of the effects of platelet lysates (HPPL) and EVs derived from SCPL. Scratch assay data shows the effects of both the full HPLs and the purified EVs from HPL are effective in the scratch assay.

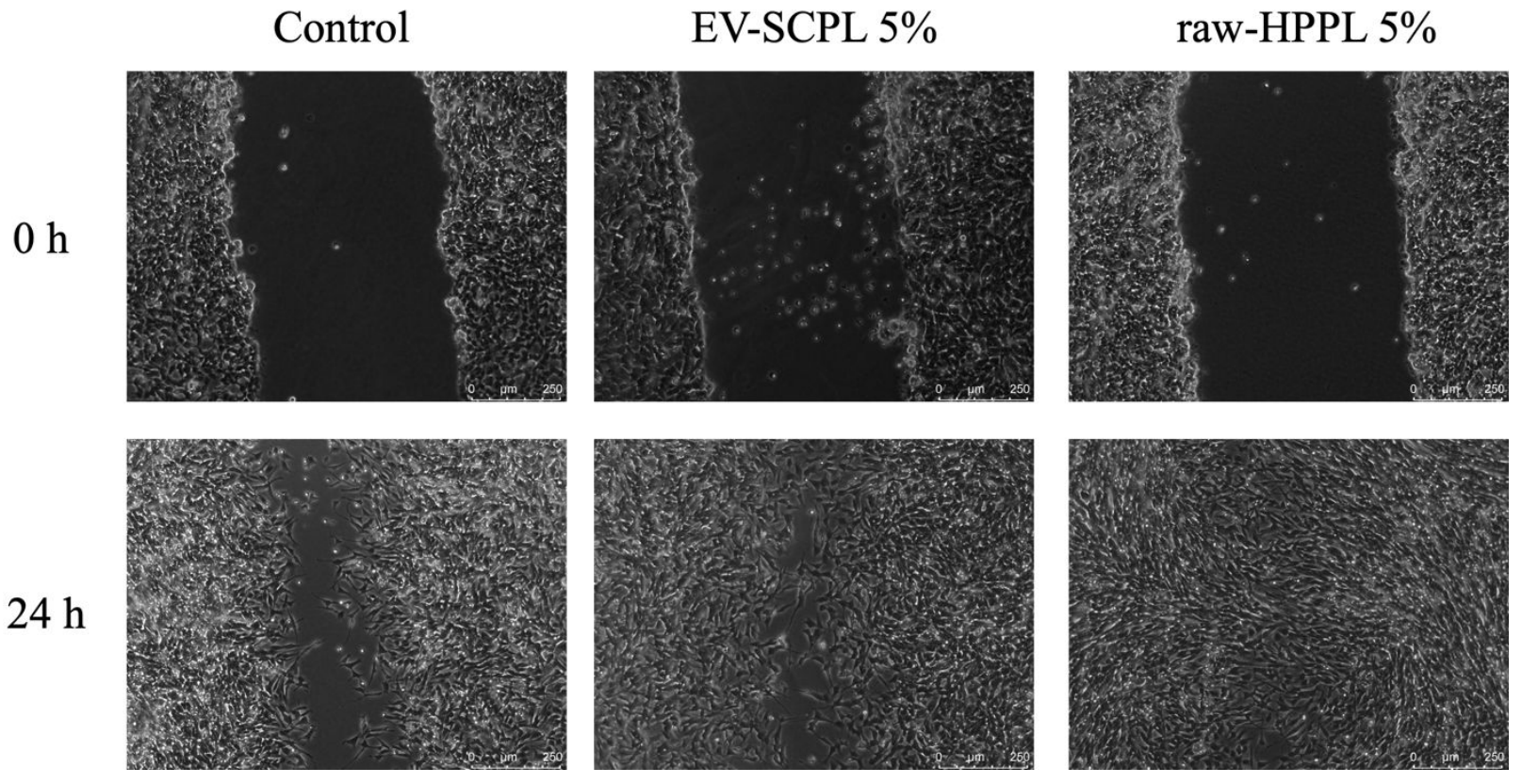


Figure S5: Primary cortical neuronal culture for functional activity evaluation of the human platelet lysate (HPPL) and EVs derived from HPLs. Primary cortical neuronal cells were used to investigated the in vitro neuroregeneration potential of the HPPL and EVs derived HPLs (EVSCPL). A) Schematic illustration of primary cortical neuronal culture and profiling assay. B) ICC (Immunocytochemistry) images of HPPL treated cells vs EV-SCPL compared with control at day DIV14 post treatment. (Scale bars: $100 \mu \mathrm{m}$ ). Preliminary results are showing that both HPPL 0.5\% $(\mathrm{v} / \mathrm{v})$ and EV-SCPL $0,5 \%(\mathrm{v} / \mathrm{v})$ promoted establishment of neuronal network as attested by enhanced bIII-tubulin and synaptophysin staining.

A.

Profiling of Synaptic assay in Primary Neuronal Cell Culture

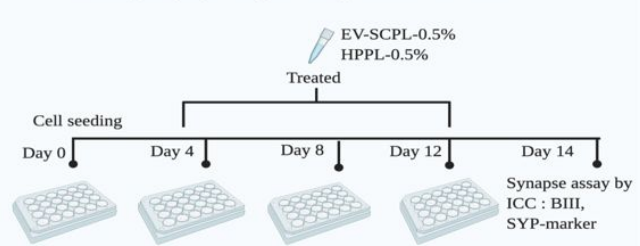

B.

Control

DIV14

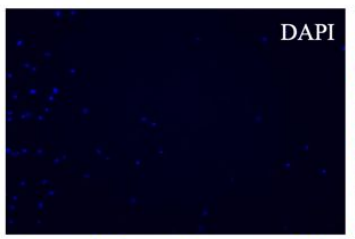

DAPI

HPPL

DIV14
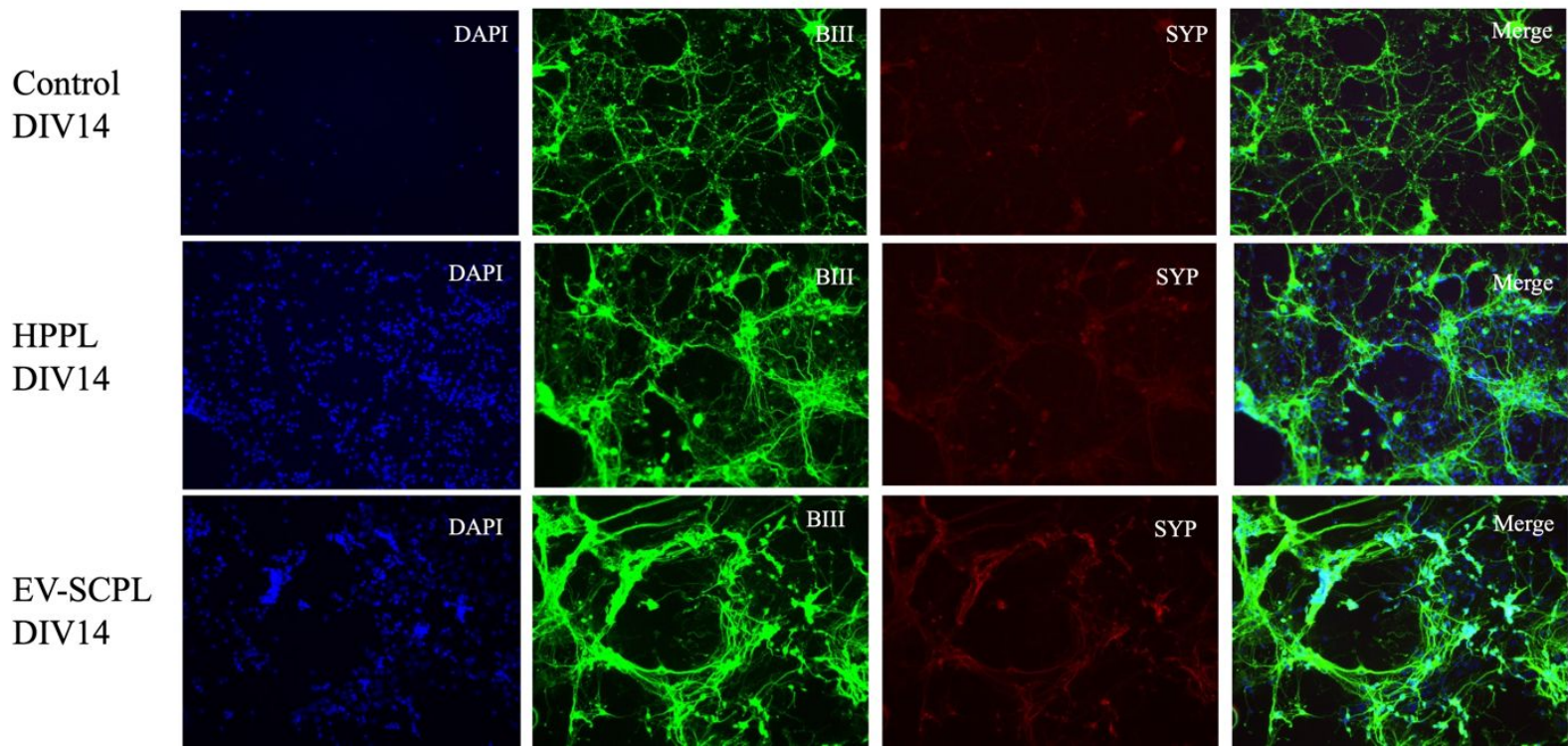

SYP
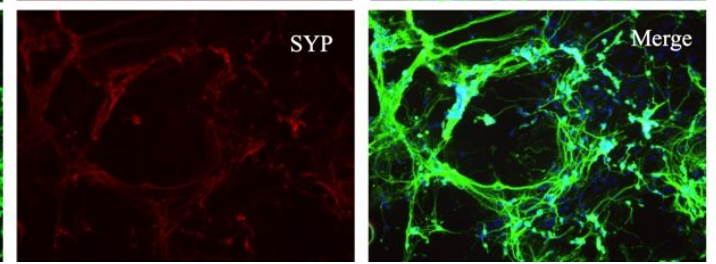


\section{References}

(1) Barro, L.; Burnouf, P. A.; Chou, M. L.; Nebie, O.; Wu, Y. W.; Chen, M. S.; Radosevic, M.; Knutson, F.; Burnouf, T., Human platelet lysates for human cell propagation. Platelets 2021, 32 (2), 152-162.

(2) Delila, L.; Wu, Y. W.; Nebie, O.; Widyaningrum, R.; Chou, M. L.; Devos, D.; Burnouf, T., Extensive characterization of the composition and functional activities of five preparations of human platelet lysates for dedicated clinical uses. Platelets 2021, 32 (2), 259-272. 